\title{
Comparing the Thermal and Electrochemical Stabilities of Two Structurally Similar Ionic Liquids
}

\author{
Faiz Ullah Shah ${ }^{1, * \mathbb{D}}$, Inayat Ali Khan ${ }^{1} \mathbb{D}$ and Patrik Johansson $2, * \mathbb{D}$ \\ 1 Chemistry of Interfaces, Luleå University of Technology, SE-971 87 Luleå, Sweden; inayat.khan@ltu.se \\ 2 Department of Physics, Chalmers University of Technology, SE-412 96 Gothenburg, Sweden \\ * Correspondence: faiz.ullah@ltu.se (F.U.S.); patrik.johansson@chalmers.se (P.J.)
}

Academic Editors: Johan Jacquemin and Fouad Ghamouss

Received: 29 April 2020; Accepted: 18 May 2020; Published: 21 May 2020

\begin{abstract}
Here we focus on the thermal and variable temperature electrochemical stabilities of two ionic liquids (ILs) having a common tributyloctyl phosphonium cation $\left[\mathrm{P}_{4,4,4,8}\right]^{+}$and two different orthoborate anions: bis(mandelato)borate $[\mathrm{BMB}]^{-}$and bis(salicylato)borate $[\mathrm{BScB}]^{-}$. The thermo-gravimetric analysis data suggest that $\left[\mathrm{P}_{4,4,4,8}\right][\mathrm{BScB}]$ is thermally more stable than $\left[\mathrm{P}_{4,4,4,8}\right][\mathrm{BMB}]$ in both nitrogen atmosphere and air, while the impedance spectroscopy reveals that $\left[\mathrm{P}_{4,4,4,8}\right][\mathrm{BSc} B]$ has higher ionic conductivity than $\left[\mathrm{P}_{4,4,4,8}\right][\mathrm{BMB}]$ over the whole studied temperature range. In contrast, the electrochemical studies confirm that $\left[\mathrm{P}_{4,4,4,8}\right][\mathrm{BMB}]$ is more stable and exhibits a wider electrochemical stability window (ESW) on a glassy carbon electrode surface as compared to $\left[\mathrm{P}_{4,4,4,8}\right][\mathrm{BScB}]$. A continuous decrease in the ESWs of both ILs is observed as a function of operation temperature.
\end{abstract}

Keywords: ionic liquids; thermo-gravimetric analysis; ionic conductivity; electrochemical stability

\section{Introduction}

Ionic liquids (ILs) are salts comprising cations and anions that form three-dimensional mobile and dynamic networks in the bulk phase. ILs are low melting salts (also known as molten salts) due to the large sizes, the nature of the molecular structures, and the high degree of asymmetry of the cations and anions. These structural features lead to weak Coulombic attractions between the ions of ILs as compared to inorganic salts [1-4]. ILs possess remarkable properties when compared with molecular liquids, making them attractive alternatives for a wide range of applications. Some of the properties of ILs include high polarity, high thermal stability (up to $450{ }^{\circ} \mathrm{C}$ ), non-volatility, high ionic conductivity, wide liquid temperature range, and structural designability $[5,6]$. The outstanding properties of ILs enable them to be promising solvents in organic synthesis [7], catalysis [8,9], lubrication [10], pharmaceuticals [11], electrochemistry [12], energy storage devices [13,14], liquid-liquid extractions [15], extraction of metals [16,17], and separation of gases [18,19].

Thermal stability of ILs is very crucial in almost all of the above-mentioned applications. A too low thermal stability might restrict the usage in various applications. However, the optimum thermal stability depends on the operation conditions of a particular application. Thermal stability of ILs is most often assessed by using thermo-gravimetric analysis (TGA) [20]. The thermal stability recorded of any IL directly depends on the purity, the atmosphere used in the TGA (usually air or an inert gas), the gas flow rate, the heating rate, and the sample mass [21]. Generally, TGA obtained thermal stabilities of ILs are defined by the $T_{\text {onset, }}$ which is calculated from the intersection of the baseline weight and the tangent of the weight loss as a function of temperature [22]. It is known that the nature of both cation and anion plays an important role in governing the thermal decomposition of ILs. Tsunashima et al. found that benzyl-substituted phosphonium ILs have much higher thermal stabilities than the analogous benzyl-substituted ammonium ILs having a common bis(trifluoromethylsulfonyl)imide 
(TFSI) anion [23]. In another study, comparing different ILs with a common phosphonium cation $\left[\mathrm{P}_{6,6,6,14}\right]^{+}$and different anions, the thermal stability was found to follow the order TFSI $>[\mathrm{FAP}]^{-}>$ $\left[\mathrm{N}(\mathrm{CN})_{2}\right]^{-}>\mathrm{Cl}^{-}>\left[\mathrm{MeSO}_{4}\right]^{-}[24]$.

Like thermal stability, electrochemical stability of ILs is an extremely important property for electrochemical applications. The electrochemical stability window (ESW) is the potential difference between the oxidation and reduction reactions and mainly depends on the nature of both cation and anion as well as the electrode material(s) used. ILs as solvents and/or electrolytes have shown numerous advantages over molecular liquids in electrochemical devices. The ESWs of ILs have been shown to exceed $6.5 \mathrm{~V}$, which is significantly larger than the ESWs of conventional organic solvents used for electrolytes; for acetonitrile the ESW is $5.0 \mathrm{~V}$, for dichloromethane $3.5 \mathrm{~V}$, and for dimethylsulfoxide $4.4 \mathrm{~V}$ [25]. It is also important to know the resulting decomposition products. When a potential wider than the ESW of the IL [ $\mathrm{C}_{4}$ mpyr]TFSI was applied, this IL decomposed into methylpyrrolidine, octanes, octenes, 2-butanol, dibutylmethylamine and butylpyrrolidine [26].

Thermal and electrochemical stabilities of ILs can be improved by an appropriate selection and combination of the cations and anions. In this work, we have chosen to study two ILs with a common $\left[\mathrm{P}_{4,4,4,8}\right]^{+}$cation and two different orthoborate anions: $[\mathrm{BMB}]^{-}$and $[\mathrm{BScB}]^{-}$(Figure 1). The choice of these two particular ILs is based on the similar chemical structures of the anions, but very different reactivity with inorganic oxide surfaces [27]. Both anions have an orthoborate $\left(\mathrm{BO}_{4}\right)$ central core, two phenyl rings and two carbonyl groups. The only difference is the presence of two $>\mathrm{CH}$ chemical moieties in the structure of the $[\mathrm{BMB}]^{-}$anion. In our previous studies, the $[\mathrm{BMB}]^{-}$anion in $\left[\mathrm{P}_{6,6,6,14}\right][\mathrm{BMB}] \mathrm{IL}$ exhibited significant changes in the structure at the surfaces of inorganic oxides such as $\gamma-\mathrm{Al}_{2} \mathrm{O}_{3}, \mathrm{MgO}$ and $\mathrm{SiO}_{2}$ as revealed by multinuclear $\left({ }^{11} \mathrm{~B},{ }^{31} \mathrm{P}\right.$ and $\left.{ }^{29} \mathrm{Si}\right)$ solid-state MAS NMR, IR and Raman spectroscopies while the $[\mathrm{BScB}]^{-}$anion in the $\left[\mathrm{P}_{6,6,6,14}\right][\mathrm{BScB}]$ IL remained unchanged, even after heating at $110^{\circ} \mathrm{C}$ for $15 \mathrm{~h}$ [27].

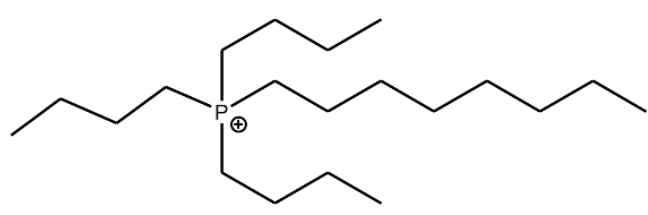

$$
\left[\mathrm{P}_{4,4,4,8}\right]^{+}
$$<smiles>O=C1O[P-]2(OC(=O)c3ccccc3O2)Oc2ccccc21</smiles>

$[\mathrm{BSCB}]^{-}$

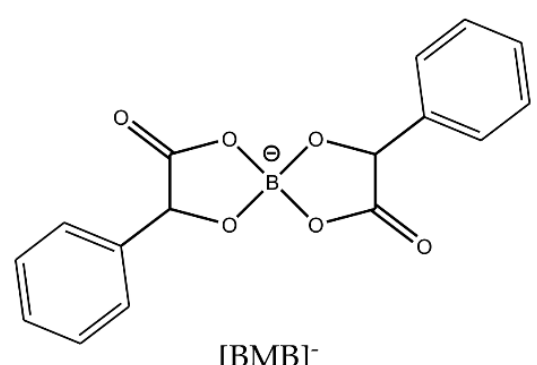

$[\mathrm{BMB}]^{-}$

Figure 1. Chemical structures and abbreviations of the IL ions.

Sustainable chemical products in general refer to the concept of ecotoxicological risk profiles, which comparatively assess five risk factors: release, spatiotemporal range, bioaccumulation, biological activity and uncertainty, and ILs often provide low risks for each of these indicators [28]. The ILs investigated here are halogen-free, hydrophobic and hydrolytically stable, which reduces the risks of corrosion, lowers the toxicity towards aquatic life and facilitates recyclability from aqueous systems, pointing to overall ecological and economical sustainability. Here we focus on the $\left[\mathrm{P}_{4,4,4,8}\right][\mathrm{BMB}]$ and $\left[\mathrm{P}_{4,4,4,8}\right][\mathrm{BSCB}]$ ILs and investigate their thermal stability both in nitrogen atmosphere and in air, 
and their electrochemical stability on the surface of a glassy carbon (GC) electrode as a function of temperature.

\section{Results and Discussion}

\subsection{Thermal Stability}

Since the applied atmosphere has a significant role in determining the thermal stability of ILs, we measured TGA both in dry nitrogen atmosphere and in air. Assessing the thermal stability of ILs under air is very important because in many practical applications the samples are in direct contact with air. Figure $2 \mathrm{a}$ shows the TGA curves of the $\left[\mathrm{P}_{4,4,4,8}\right][\mathrm{BMB}]$ and $\left[\mathrm{P}_{4,4,4,8}\right][\mathrm{BScB}]$ ILs under nitrogen and air using identical experimental conditions. Both ILs show major weight loss in a single step, indicating that both the cation and the anion decompose within a narrow temperature range. The TGA data show that $\left[\mathrm{P}_{4,4,4,8}\right][\mathrm{BScB}]$ is thermally more stable $\left(T_{\text {onset }}\right.$ are $412{ }^{\circ} \mathrm{C}$ in $\mathrm{N}_{2}$ and $322{ }^{\circ} \mathrm{C}$ in air) than $\left[\mathrm{P}_{4,4,4,8}\right][\mathrm{BMB}]\left(T_{\text {onset }}\right.$ are $403{ }^{\circ} \mathrm{C}$ in $\mathrm{N}_{2}$ and $305^{\circ} \mathrm{C}$ in air). Thus, both ILs decompose at much lower temperatures in air, but despite these lower decomposition temperatures, $14.4 \mathrm{wt} . \%$ and $18.2 \mathrm{wt}$.\% of $\left[\mathrm{P}_{4,4,4,8}\right][\mathrm{BMB}]$ and $\left[\mathrm{P}_{4,4,4,8}\right][\mathrm{BScB}]$, respectively, remained after heating to $600{ }^{\circ} \mathrm{C}$. On the other hand, only $7.1 \mathrm{wt} \%$ and $6.5 \mathrm{wt}$ \% of the decomposition products from $\left[\mathrm{P}_{4,4,4,8}\right][\mathrm{BMB}]$ and $\left[\mathrm{P}_{4,4,4,8}\right][\mathrm{BScB}]$, respectively, remained after heating to $600{ }^{\circ} \mathrm{C}$ in nitrogen atmosphere. This is in agreement with a previously published report on the thermal stability of phosphonium-based ILs [29] stating that the decomposition of phosphonium-based ILs under air might lead to the formation of tertiary phosphines, through a reversed Menshutkin reaction, which can be further oxidized to form tertiary phosphine oxides, which are thermally very stable species [30]. The lower thermal stability of these ILs in air might be due to oxidation of the $\left[\mathrm{P}_{4,4,4,8}\right]^{+}$cation followed by an accelerated decomposition of the $[\mathrm{BMB}]^{-}$and $[\mathrm{BScB}]^{-}$anions.
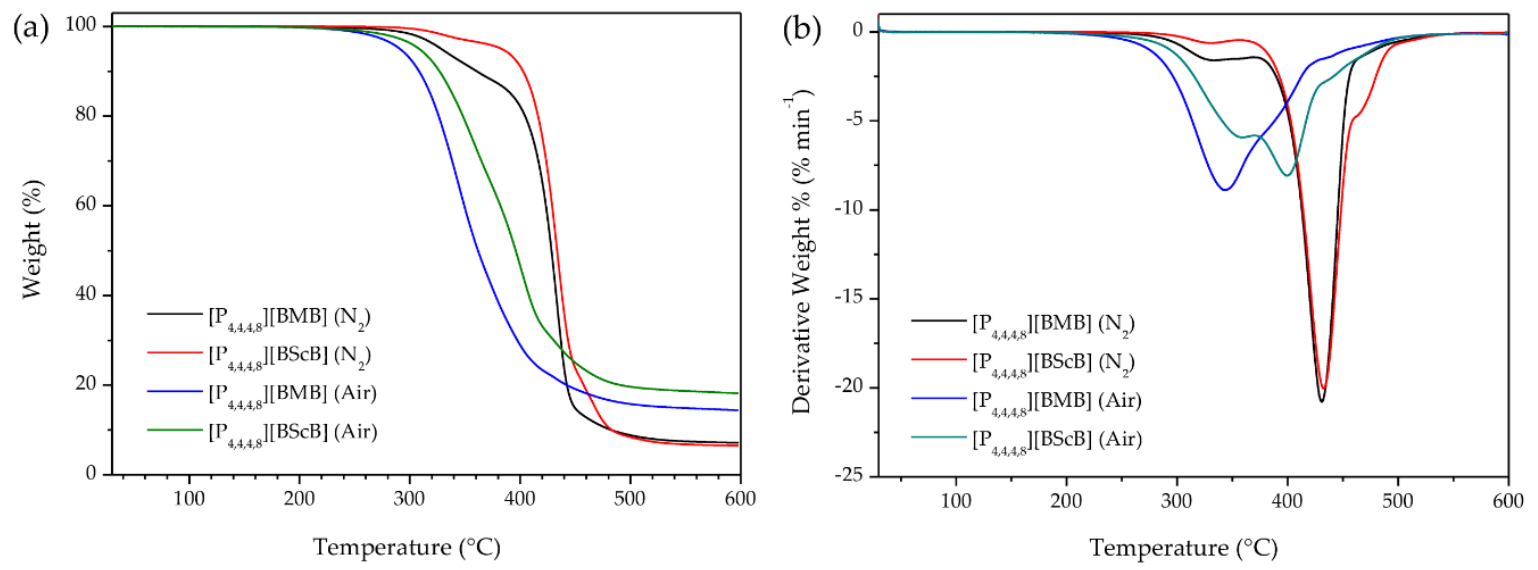

Figure 2. (a) TGA thermograms and (b) DTG curves of ILs under nitrogen atmosphere and in air at a heating rate of $10{ }^{\circ} \mathrm{C} \mathrm{min}^{-1}$.

The derivative thermogravimetric (DTG) curves, i.e., weight loss per time-unit and temperature, showed that the rate of weight loss for both $\left[\mathrm{P}_{4,4,4,8}\right][\mathrm{BMB}]\left(21 \mathrm{wt} . \% \mathrm{~min}^{-1}\right)$ and $\left[\mathrm{P}_{4,4,4,8}\right][\mathrm{BScB}]$ (20 wt. $\%$ min $^{-1}$ ) under $\mathrm{N}_{2}$ is maximal at ca. $430{ }^{\circ} \mathrm{C}$ (with shoulders on both sides) (Figure $2 b$ ). However, this changes when exposed to air; the highest rates of weight loss are much lower: $9 \mathrm{wt} . \% \mathrm{~min}^{-1}$ at $344{ }^{\circ} \mathrm{C}$ for $\left[\mathrm{P}_{4,4,4,8}\right][\mathrm{BMB}]$ and $8 \mathrm{wt} . \% \mathrm{~min}^{-1}$ at $402{ }^{\circ} \mathrm{C}$ for $\left[\mathrm{P}_{4,4,4,8}\right][\mathrm{BScB}]$, again with shoulders on one side $\left(\left[\mathrm{P}_{4,4,4,8}\right][\mathrm{BMB}]\right)$ and both sides $\left(\left[\mathrm{P}_{4,4,4,8}\right][\mathrm{BScB}]\right)$. The lower rates of weight loss might be due to a high thermal stability of the tertiary phosphine oxides formed.

The thermal stabilities of these ILs are better and/or comparable with other commonly studied ILs based on imidazolium, ammonium and phosphonium cations combined with conventional anions such as halides, $\mathrm{BF}_{4}, \mathrm{PF}_{6}$, etc. Ngo et al. studied a range of imidazolium-based ILs with halogenated anions and most decomposed below $400{ }^{\circ} \mathrm{C}$, with the exception of ILs with the TFSI anion [31]. 
For ten different phosphonium and ammonium cation-based ILs with a common dicyanamide anion, the phosphonium-based were found to be relatively more stable $\left(T_{\mathrm{dec}}<400{ }^{\circ} \mathrm{C}\right)$ than the ammonium-based $\left(T_{\mathrm{dec}}<300{ }^{\circ} \mathrm{C}\right)$ [32].

\subsection{Ionic Conductivity}

Ionic conductivity of ILs is generally controlled by the size and molecular weight of cation and anion, density and viscosity, and the interactions between the ions-the latter is one the main reasons for ion-pairing, and thereby reduced ionic conductivity [33-35]. A comparison of the ionic conductivities of the $\left[\mathrm{P}_{4,4,4,8}\right][\mathrm{BMB}]$ and $\left[\mathrm{P}_{4,4,4,8}\right][\mathrm{BScB}] \mathrm{ILs}$ in the range from $-20{ }^{\circ} \mathrm{C}$ to $100{ }^{\circ} \mathrm{C}$ is shown in Figure 3, wherein $\left[\mathrm{P}_{4,4,4,8}\right][\mathrm{BMB}]$ has lower ionic conductivity than $\left[\mathrm{P}_{4,4,4,8}\right][\mathrm{BScB}]$ throughout the whole temperature range. This was expected as $\left[\mathrm{P}_{4,4,4,8}\right][\mathrm{BMB}]$ has a higher viscosity than $\left[\mathrm{P}_{4,4,4,8}\right][\mathrm{BScB}][36]$. It is well known that viscous ILs with bulky and asymmetric ions display lower ionic conductivities due to hindered mobility of ions [37]. The higher ionic conductivity of $\left[\mathrm{P}_{4,4,4,8}\right][\mathrm{BScB}]$ can also be justified by the relatively lower molecular weight of the $[\mathrm{BScB}]^{-}$anion $\left(283.0 \mathrm{~g} \mathrm{~mol}^{-1}\right)$ as compared to the $[\mathrm{BMB}]^{-}$anion $\left(311.0 \mathrm{~g} \mathrm{~mol}^{-1}\right)$ and its more compact chemical structure.

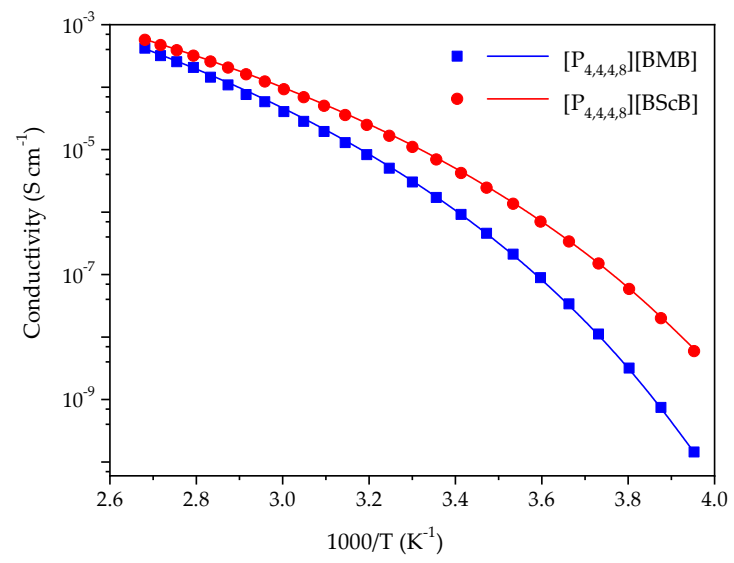

Figure 3. Temperature dependence of the ionic conductivities for $\left[\mathrm{P}_{4,4,4,8}\right][\mathrm{BMB}]$ and $\left[\mathrm{P}_{4,4,4,8}\right][\mathrm{BScB}]$ and the best fit of data using the VFT equation as indicated by the solid lines.

The ionic conductivity data were analyzed further by fitting to the Vogel-Fulcher-Tammann (VFT) equation, which is commonly used to describe the ionic conductivity of ILs [38]:

$$
\sigma=\sigma_{0} \exp \left(\frac{-B}{\left(T-T_{0}\right)}\right)
$$

where $\sigma_{0}, B$, and $T_{0}$ are fitting parameters: a pre-exponential factor, a factor related to the activation and the ideal glass transition temperature, respectively. The activation energy for ionic conductivity $(\mathrm{E} \sigma)$ is related to $\mathrm{B}$ as $\mathrm{E} \sigma=B \times R$. The fitting procedure was carried out over the full temperature range in two steps. In the first step, we plot $\ln (\sigma)$ vs. $1 /\left(T-T_{0}\right)$ and selected $T_{0}$ to have a linear dependence. In the second step, we fit the dependence by a linear regression to obtain the fitting parameters $\left(\sigma_{0}, B\right)$. The VFT parameters (Table 1$)$ show that the $E \sigma$ of $\left[\mathrm{P}_{4,4,4,8}\right][\mathrm{BMB}]$ is slightly higher than for $\left[\mathrm{P}_{4,4,4,8}\right][\mathrm{BScB}]$, which was expected, as the ionic conductivity of the latter is higher. This reveals that relatively lower thermal energy is required for ion mobility in the case of $\left[\mathrm{P}_{4,4,4,8}\right][\mathrm{BScB}]$.

Table 1. VFT equation parameters and activation energies for the ionic conductivity data of the ILs.

\begin{tabular}{|c|c|c|c|c|}
\hline IL & $\sigma_{0}\left(S \mathrm{~cm}^{-1}\right)$ & $B(\mathrm{~K})$ & $T_{0}(\mathrm{~K})$ & $E \sigma\left(\mathrm{kJ} \mathrm{mol}^{-1} \mathrm{~K}^{-1}\right)$ \\
\hline$\left[\mathrm{P}_{4,4,4,8}\right][\mathrm{BMB}]$ & 1.15 & 1460 & 189 & 12.1 \\
\hline$\left[\mathrm{P}_{4,4,4,8}\right][\mathrm{BScB}]$ & 0.50 & 1290 & 182 & 10.7 \\
\hline
\end{tabular}




\subsection{Electrochemical Stability}

Variable temperature cyclic voltammetry (CV) and linear sweep voltammetry (LSV) were both employed to evaluate the electrochemical stabilities of the ILs. Figure 4 illustrates a comparison of the cyclic voltammograms for the $\left[\mathrm{P}_{4,4,4,8}\right][\mathrm{BMB}]$ and $\left[\mathrm{P}_{4,4,4,8}\right][\mathrm{BScB}]$ ILs at $20^{\circ} \mathrm{C}$ (the complete five cycles are shown in Figures $\mathrm{S} 2$ and $\mathrm{S} 4)$. $\left[\mathrm{P}_{4,4,4,8}\right][\mathrm{BMB}]$ is clearly electrochemically more stable than $\left[\mathrm{P}_{4,4,4,8}\right][\mathrm{BScB}]$ at the surface of the GC electrode. In addition, a significantly higher background current is produced by $\left[\mathrm{P}_{4,4,4,8}\right][\mathrm{BSCB}]$ than $\left[\mathrm{P}_{4,4,4,8}\right][\mathrm{BMB}]$, indicating that the former IL is more electroactive and involved in rapid electron transfer with the electrode surface. The variable temperature cyclic voltammograms for both $\left[\mathrm{P}_{4,4,4,8}\right][\mathrm{BMB}]$ and $\left[\mathrm{P}_{4,4,4,8}\right][\mathrm{BScB}]$ ILs are shown in Figures $\mathrm{S} 1$ and $\mathrm{S} 3$, and reveal electrochemical stability and reversibility of the cathodic and anodic reactions occurring in these ILs in the applied potential limits also at elevated temperatures.

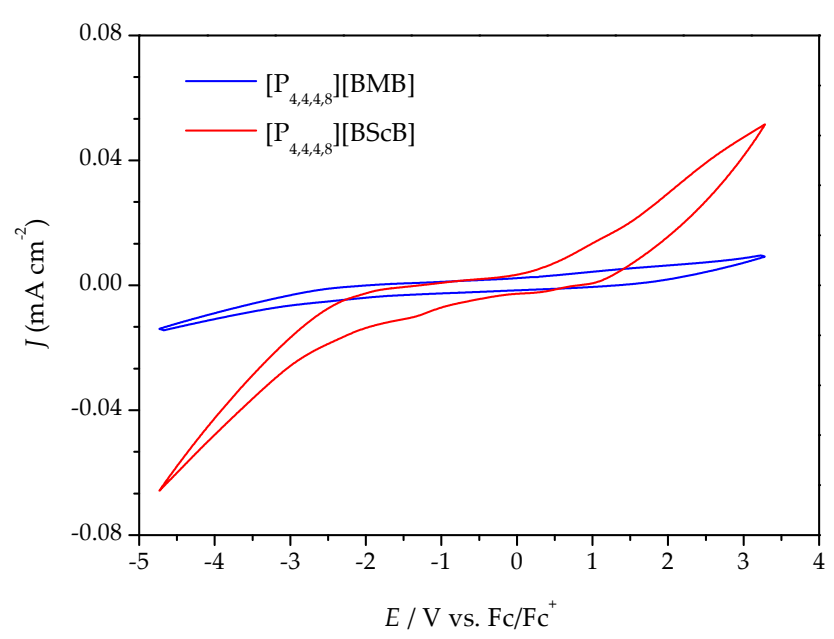

Figure 4. Cyclic voltammograms of the ILs at a GC electrode at $20{ }^{\circ} \mathrm{C}$ and a $100 \mathrm{mV} \mathrm{s}^{-1}$ potential sweep rate.

The ESWs were determined in more detail by using LSV over a temperature range from $0{ }^{\circ} \mathrm{C}$ to $80{ }^{\circ} \mathrm{C}$. The ESW of $\left[\mathrm{P}_{4,4,4,8}\right][\mathrm{BMB}]$ is much wider than for $\left[\mathrm{P}_{4,4,4,8}\right][\mathrm{BScB}]$ for all temperatures (Figures 5 and 6, Table S1). For example, at $20^{\circ} \mathrm{C}$, the ESWs of $\left[\mathrm{P}_{4,4,4,8}\right][\mathrm{BMB}]$ and $\left[\mathrm{P}_{4,4,4,8}\right][\mathrm{BScB}]$ are $7.31 \mathrm{~V}$ and $3.97 \mathrm{~V}$, respectively. The significantly lower ESW of $\left[\mathrm{P}_{4,4,4,8}\right][\mathrm{BScB}]$ is unexpected, as the $[\mathrm{BScB}]^{-}$anion has previously been shown to have excellent chemical stability in comparison to the $[\mathrm{BMB}]^{-}$anion at the surfaces of $\gamma-\mathrm{Al}_{2} \mathrm{O}_{3}, \mathrm{MgO}$ and $\mathrm{SiO}_{2}$ [27]. Obviously, the applied potential and/or electrode surface makes a difference.

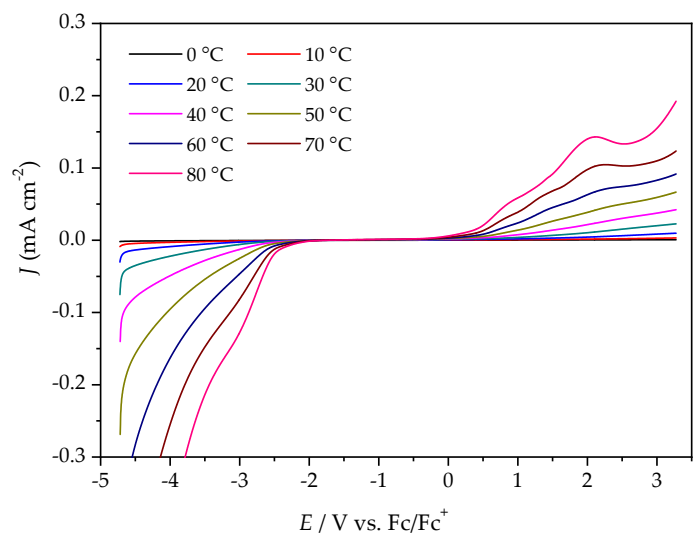

Figure 5. LSV of $\left[\mathrm{P}_{4,4,4,8}\right][\mathrm{BMB}]$ at a GC electrode, different temperatures and a scan rate of $20 \mathrm{mV} \mathrm{s}^{-1}$. 


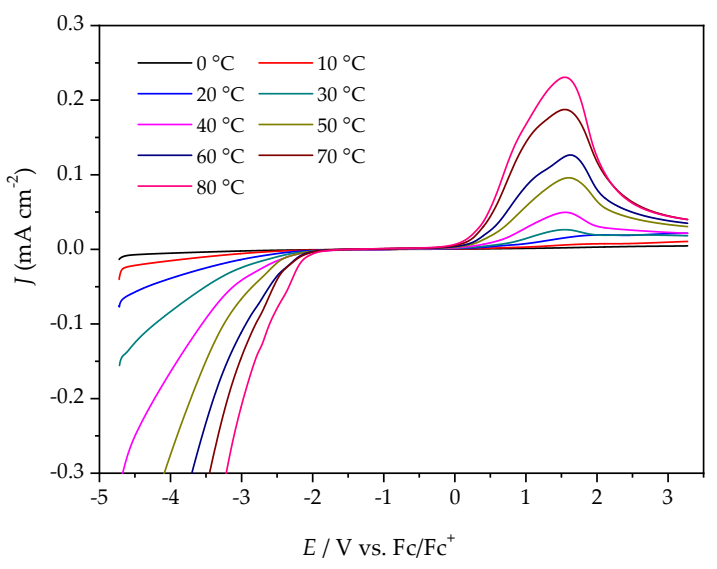

Figure 6. LSV of $\left[\mathrm{P}_{4,4,4,8}\right][\mathrm{BScB}]$ at a GC electrode, different temperatures, and a scan rate of $20 \mathrm{mV} \mathrm{s}^{-1}$.

An increased operating temperature often leads to a narrower ESW, as also predicted by the Nernst equation [39]. For example, Chavan et al. observed a decrease in the ESWs of ILs containing ether and siloxane functionalized imidazolium-based cations and the TFSI anion [40]. Here we observe a sharp decrease in the ESW width for both $\left[\mathrm{P}_{4,4,4,8}\right][\mathrm{BMB}]$ and $\left[\mathrm{P}_{4,4,4,8}\right][\mathrm{BScB}]$ as a function of temperature (Figure 7), with a large decrease for both ILs between $10^{\circ} \mathrm{C}$ and $20^{\circ} \mathrm{C}$. This might be due to the lowered viscosity resulting in a higher ionic conductivity, and the dissociation of ions of the ILs leading to a faster ion diffusivity and more frequent contacts with the surface of electrode. The anodic potential $\left(E_{\mathrm{A}}\right)$ is more affected than the cathodic potential $\left(E_{C}\right)$, indicating that the borate anions are more sensitive to the temperature increase than the $\left[\mathrm{P}_{4,4,4,8}\right]^{+}$cation.

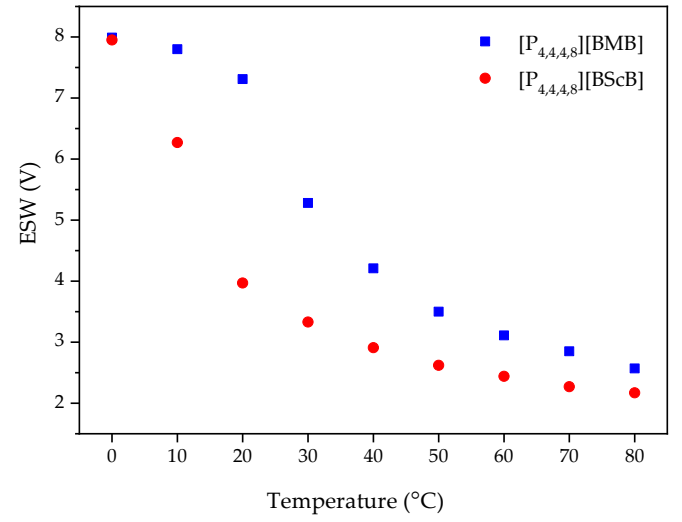

Figure 7. ESWs as a function of temperature for the ILs using a GC electrode.

Another plausible reason for the reduction in ESWs at elevated temperatures might be the traces of water present in both these ILs. Schröder et al. found that the ESWs of ILs are significantly decreased in the presence of even very small amount of water [41]. It has also recently been revealed, through systematic molecular dynamic simulations, that the water molecules present in ILs based on [BMB] ${ }^{-}$ and $[\mathrm{BScB}]^{-}$anions are specifically located around the central polar segment of the anions to avoid direct contact with the hydrophobic phenyl rings [42]. Furthermore, the water molecules are embedded in the cavities between ions of the ILs and result in the formation of intermolecular hydrogen bonds between the water molecules and the anions. Such interactions facilitate microscopic liquid structures through ion-water-ion multiple complexes that make it very difficult to remove these water molecules by using vacuum and temperature treatments. Therefore, the shoulder around $1 \mathrm{~V}$ in the LSV curves of both $\left[\mathrm{P}_{4,4,4,8}\right][\mathrm{BMB}]$ and $\left[\mathrm{P}_{4,4,4,8}\right][\mathrm{BScB}]$, more prominent at elevated temperatures, might be due to the release of water molecules at the surface of electrode under the applied potential that previously were strongly trapped in the three-dimensional organization of the ILs [43]. 
Altogether, the ESW data suggest that $\left[\mathrm{P}_{4,4,4,8}\right][\mathrm{BMB}]$ is electrochemically more stable than $\left[\mathrm{P}_{4,4,4,8}\right][\mathrm{BScB}]$, while the latter is thermally and chemically more stable. This is in accordance with the results by Mun et al. [44] showing that 1-ethyl-3-methylimidazolium (emim) TFSI has a lower electrochemical stability both at $20^{\circ} \mathrm{C}$ and $120^{\circ} \mathrm{C}$ as compared to both $\left[\mathrm{C}_{3} \mathrm{mpy}\right] \mathrm{TFSI}$ and $\left[\mathrm{C}_{4} \mathrm{mpip}\right] \mathrm{TFSI}$, despite that [emim]TFSI is thermally more stable.

\section{Materials and Methods}

\subsection{Materials}

The synthesis and characterization of $\left[\mathrm{P}_{4,4,4,8}\right][\mathrm{BMB}]$ and $\left[\mathrm{P}_{4,4,4,8}\right][\mathrm{BScB}]$ are described in detail in our previous publication [36]. The samples were kept in a vacuum oven at $80{ }^{\circ} \mathrm{C}$ for 5 days prior to measurements. The water contents were $600 \pm 50 \mathrm{ppm}$ and $200 \pm 40 \mathrm{ppm}$ in $\left[\mathrm{P}_{4,4,4,8}\right][\mathrm{BMB}]$ and $\left[\mathrm{P}_{4,4,4,8}\right][\mathrm{BScB}]$, respectively, as determined by Karl Fischer titration using 917 coulometer (Metrohm, Herisau, Switzerland). Efforts were made to minimize the amount of water, but due to the strong interactions between the water molecules and the anions of these ILs, it was impossible to remove all traces of water [42].

\subsection{Thermal Stability}

Thermo-gravimetric analysis (TGA) was performed using a Perkin Elmer 8000 TGA (Perkin Elmer, Waltham, MA, United States) apparatus. The dynamic TGA experiments were performed at a heating rate of $10^{\circ} \mathrm{C}$ min under nitrogen gas and air. About $4 \mathrm{mg}$ of IL was used for each experiment.

\subsection{Ionic Conductivity}

A Metrohm Autolab PGSTAT302N electrochemical workstation (Metrohm Autolab, Utrecht, The Netherlands) with an FRA32M module for impedance measurements, all controlled by the Nova 2.02 software (Metrohm Autolab, Utrecht, The Netherlands), was used. The ionic conductivities were measured in the frequency range from $1 \mathrm{~Hz}$ to $1 \mathrm{MHz}$ using $10 \mathrm{mV}_{\mathrm{rms}} \mathrm{AC}$ voltage amplitude and in the temperature range from $-20^{\circ} \mathrm{C}$ to $100{ }^{\circ} \mathrm{C}$. A two-electrode set-up was used with a $2 \mathrm{~mm}$ diameter glassy carbon (GC) working electrode and a $70 \mu \mathrm{L}$ Pt cup as a sample container as well as counter electrode. Both the electrodes were polished with a Kemet diamond paste $0.25 \mu \mathrm{m}$ prior to each measurement. The cell constant was determined by using a $100 \mu \mathrm{S} \mathrm{cm}^{-1} \mathrm{KCl}$ standard solution from Metrohm (Metrohm, Herisau, Switzerland) $\left(\right.$ Kcell $\left.=1.486 \mathrm{~cm}^{-1}\right)$. The cell was thermally equilibrated for $10 \mathrm{~min}$ before each measurement.

\subsection{Electrochemical Stability}

A sample of about $70 \mu \mathrm{L}$ was placed in a sealed TSC 70 cell coupled with temperature-controlled Microcell HC (RHD instruments, Darmstadt, Germany). Cyclic voltammetry (CV) and linear sweep voltammetry (LSV) experiments were performed in the temperature range from $0{ }^{\circ} \mathrm{C}$ to $80{ }^{\circ} \mathrm{C}$ using a three electrode set-up: GC as a working electrode (WE), Pt cup as a counter electrode (CE) and an $\mathrm{Ag}$ wire coated with $\mathrm{AgCl}$ was used as a pseudo-reference electrode (RE). The cyclic voltammograms were recorded at a scan rate of $100 \mathrm{mV} \mathrm{s}^{-1}$ while the linear sweeps voltammograms were recorded at $20 \mathrm{mV} \mathrm{s}^{-1}$. The potential values were converted to ferrocene reference as an internal standard. The ESW limits were determined from LSV curves using a $0.01 \mathrm{~mA} \mathrm{~cm}^{-1}$ cut-off current density [45].

\section{Conclusions}

Two phosphonium-orthoborate ILs, $\left[\mathrm{P}_{4,4,4,8}\right][\mathrm{BMB}]$ and $\left[\mathrm{P}_{4,4,4,8}\right][\mathrm{BScB}]$, with the same cation and structurally very similar anions, show different thermal and electrochemical stabilities. $\left[\mathrm{P}_{4,4,4,8}\right][\mathrm{BScB}]$ has a higher thermal stability both in nitrogen atmosphere and in air, and higher ionic conductivity, but has lower electrochemically stability. On the other hand, $\left[\mathrm{P}_{4,4,4,8}\right][\mathrm{BMB}]$ exhibits higher electrochemical stability, but lower thermal stability and ionic conductivity. As expected, the ESW of 
both ILs significantly decrease as a function of temperature. These findings suggest that there is no direct relation between thermal stability, chemical reactivity, and electrochemical stability. An IL can be thermally less stable, but chemically more stable, and vice versa. This study suggests that $\left[\mathrm{P}_{4,4,4,8}\right][\mathrm{BMB}]$ is suitable for applications where high electrochemical stability is required and $\left[\mathrm{P}_{4,4,4,8}\right][\mathrm{BScB}]$ can be used in applications where large electrochemical stability is not very important, but where thermal and chemical stability is essential.

Supplementary Materials: The following are available online at http://www.mdpi.com/1420-3049/25/10/2388/s1.

Author Contributions: Conceptualization, F.U.S., I.A.K. and P.J.; methodology, F.U.S., I.A.K. and P.J.; formal analysis, F.U.S. and I.A.K.; funding acquisition, F.U.S. and P.J.; data curation, F.U.S. and I.A.K.; writing-original draft preparation, F.U.S.; writing-review and editing, F.U.S., I.A.K. and P.J. All authors have read and agreed to the published version of the manuscript.

Funding: The financial support from the Swedish Research Council (project number: 2018-04133) is gratefully acknowledged. PJ is grateful for the continuous support from several of Chalmers' Areas of Advance: Materials Science, Energy, and Transport. The APC was funded by MDPI.

Conflicts of Interest: The authors declare no conflict of interest.

\section{References}

1. Welton, T. Room-temperature ionic liquids. Solvents for synthesis and catalysis. Chem. Rev. 1999, 99, 2071-2083. [CrossRef]

2. MacFarlane, D.R.; Pringle, J.M.; Howlett, P.C.; Forsyth, M. Ionic liquids and reactions at the electrochemical interface. Phys. Chem. Chem. Phys. 2010, 12, 1659-1669. [CrossRef]

3. Petkovic, M.; Seddon, K.; Pereira, C. Ionic liquids: A pathway to environmental acceptability. Chem. Soc. Rev. 2011, 40, 1383-1403. [CrossRef]

4. Shah, F.U.; Glavatskih, S.; Dean, P.M.; MacFarlane, D.R.; Forsyth, M.; Antzutkin, O.A. Halogen-free chelated orthoborate ionic liquids and organic ionic plastic crystals. J. Mater. Chem. 2012, 22, 6928-6938. [CrossRef]

5. Hallett, J.; Welton, T. Room-temperature ionic liquids: Solvents for synthesis and catalysis. Chem. Rev. 2011, 111, 3508-3576. [CrossRef]

6. Plechkova, N.; Seddon, K. Applications of ionic liquids in the chemical industry. Chem. Soc. Rev. 2008, 37, 123-150. [CrossRef]

7. Handy, S.T.; Okello, M. Homogeneous supported synthesis using ionic liquid supports: Tunable separation properties. J. Org. Chem. 2005, 70, 2874-2877. [CrossRef]

8. Parvulescu, V.I.; Hardacre, C. Catalysis in ionic liquids. Chem. Rev. 2007, 207, 2615-2665. [CrossRef]

9. Brown, R.J.; Dyson, P.J.; Ellis, D.; Welton, T. 1-Butyl-3-methylimidazolium cobalt tetracarbonyl [bmim] $\left[\mathrm{Co}(\mathrm{CO})_{4}\right]$ : A catalytically active organometallic ionic liquid. Chem. Commun. 2001, 1862-1863. [CrossRef]

10. Shah, F.U.; Glavatskih, S.; Antzutkin, O.N. Boron in tribology: From borates to ionic liquids. Tribol. Lett. 2013, 51, 281-301. [CrossRef]

11. Shimpi, M.R.; Velaga, S.P.; Shah, F.U.; Antzutkin, O.N. Pharmaceutical crystal engineering using ionic liquid anion-solute interactions. Cryst. Growth Des. 2017, 17, 1729-1734. [CrossRef]

12. MacFarlane, D.R.; Forsyth, M.; Howlett, P.C.; Pringle, J.M.; Sun, J.; Annat, G.; Neil, W.; Izgorodina, E.I. Ionic liquids in electrochemical devices and processes: Managing interfacial electrochemistry. Acc. Chem. Res. 2007, 40, 1165-1173. [CrossRef]

13. Scheers, J.; Fantini, S.; Johansson, P. A review of electrolytes for lithium-sulphur batteries. J. Power Sources 2014, 255, 204-218. [CrossRef]

14. Zhong, C.; Deng, Y.; Hu, W.; Qiao, J.; Zhang, L.; Zhang, J. A review of electrolyte materials and compositions for electrochemical supercapacitors. Chem. Soc. Rev. 2015, 44, 7484-7539. [CrossRef]

15. Dietz, M.L.; Dzielawa, J.A. Ion-exchange as a mode of cation transfer into room temperature ionic liquids containing crown ethers: Implications for the 'greenness' of ionic liquids as diluents in liquid-liquid extraction. Chem. Commun. 2001, 2124-2125. [CrossRef]

16. Luo, H.; Dai, S.; Bonnesen, P.V. Solvent extraction of $\mathrm{Sr}^{2+}$ and $\mathrm{Cs}^{+}$based on room temperature ionic liquids containing monoaza-substituted crown ethers. Anal. Chem. 2004, 76, 2773-2779. [CrossRef] 
17. Chun, S.; Dzyuba, S.V.; Bartsch, R.A. Influence of structural variation in room temperature ionic liquids on the selectivity and efficiency of competitive alkali metal salt extraction by a crown ether. Anal. Chem. 2001, 73, 3737-3741. [CrossRef]

18. Bhattacharyya, S.; Filippov, A.; Shah, F.U. Insights into the effect of $\mathrm{CO}_{2}$ absorption on the ionic mobility of ionic liquids. Phys. Chem. Chem. Phys. 2016, 18, 28617-28625. [CrossRef]

19. Bhattacharyya, S.; Shah, F.U. Ether functionalized choline tethered amino acid ionic liquids for enhanced $\mathrm{CO}_{2}$ capture. ACS Sustain. Chem. Eng. 2016, 4, 5441-5449. [CrossRef]

20. Maton, C.; Vos, N.D.; Stevens, C.V. Ionic liquid thermal stabilities: Decomposition mechanisms and analysis tools. Chem. Soc. Rev. 2013, 42, 5963-5977. [CrossRef]

21. Kosmulski, M.; Gustafsson, J.; Rosenholm, J.B. Thermal stability of low temperature ionic liquids revisited. Thermochim. Acta 2004, 412, 47-53. [CrossRef]

22. Del Sesto, R.E.; McCleskey, T.M.; Macomber, C.; Ott, K.C.; Koppisch, A.T.; Baker, G.A.; Burrell, A.K. Limited thermal stability of imidazolium and pyrrolidinium ionic liquids. Thermochim. Acta 2009, 491, 118-120. [CrossRef]

23. Tsunashima, K.; Niwa, E.; Kodama, S.; Sugiya, M.; Ono, Y. Thermal and transport properties of ionic liquids based on benzyl-substituted phosphonium cations. J. Phys. Chem. B 2009, 113, 15870-15874. [CrossRef]

24. Ferreira, A.F.; Simões, P.N.; Ferreira, A.G.M. Quaternary phosphonium-based ionic liquids: Thermal stability and heat capacity of the liquid phase. J. Chem. Thermodyn. 2012, 45, 16-27. [CrossRef]

25. Barrosse-Antle, L.E.; Bond, A.M.; Compton, R.G.; O'Mahony, A.M.; Rogers, E.I.; Silvester, D.S. Voltammetry in room temperature ionic liquids: Comparisons and contrasts with conventional electrochemical solvents. Chem. Asian J. 2010, 5, 202-230. [CrossRef]

26. Kroon, M.C.; Buijs, W.; Peters, C.J.; Witkamp, G.J. Decomposition of ionic liquids in electrochemical processing. Green Chem. 2006, 8, 241-245. [CrossRef]

27. Shah, F.U.; Holmgren, A.; Rutland, M.W.; Glavatskih, S.; Antzutkin, O.N. Interfacial behavior of orthoborate ionic liquids at inorganic oxide surfaces probed by NMR, IR and Raman spectroscopy. J. Phys. Chem. C 2018, 122, 19687-19698. [CrossRef]

28. Ranke, J.; Stolte, S.; Störmann, R.; Arning, J.; Jastorff, B. Design of sustainable chemical products-The example of ionic liquids. Chem. Rev. 2007, 107, 2183-2206. [CrossRef]

29. Deferm, C.; den Bossche, A.V.; Luyten, J.; Oosterhof, H.; Fransaer, J.; Binnemans, K. Thermal stability of trihexyl(tetradecyl)phosphonium chloride. Phys. Chem. Chem. Phys. 2018, 20, 2444-2456. [CrossRef]

30. Corbridge, D.E.C. Phosphorus: An Outline of Its Chemistry, Biochemistry, and Technology; CRC Press: Boca Raton, FL, USA, 2013.

31. Ngo, H.L.; LeCompte, K.; Hargens, L.; McEwen, A.B. Thermal properties of imidazolium ionic liquids. Thermochim. Acta 2000, 357-358, 97-102. [CrossRef]

32. Tsunashima, K.; Kodama, S.; Sugiya, M.; Kunugi, Y. Physical and electrochemical properties of room-temperature dicyanamide ionic liquids based on quaternary phosphonium cations. Electrochimi. Acta 2010, 56, 762-766. [CrossRef]

33. MacFarlane, D.R.; Forsyth, M.; Izgorodina, E.I.; Abbott, A.P.; Annat, G.; Fraser, K. On the concept of ionicity in ionic liquids. Phys. Chem. Chem. Phys. 2009, 11, 4962-4967. [CrossRef]

34. Ueno, K.; Tokuda, H.; Watanabe, M. Ionicity in ionic liquids: Correlation with ionic structure and physicochemical properties. Phys. Chem. Chem. Phys. 2010, 12, 1649-1658. [CrossRef]

35. Nilsson-Hallén, J.; Ahlström, B.; Marczewski, M.; Johansson, P. Ionic liquids: A simple model to predict ion conductivity based on DFT derived physical parameters. Front. Chem. 2019, 7, 00126. [CrossRef]

36. Shah, F.U.; Glavatskih, S.; MacFarlane, D.R.; Forsyth, M.; Antzutkin, O.N. Novel halogen-free chelated orthoborate-phosphonium ionic liquids: Synthesis and tribophysical properties. Phys. Chem. Chem. Phys. 2011, 13, 12865-12873. [CrossRef]

37. Tsuzuki, S.; Tokuda, H.; Hayamizu, K.; Watanabe, M. Magnitude and directionality of interaction in ion pairs of ionic liquids: Relationship with ionic conductivity. J. Phys. Chem. B 2005, 109, 16474-16481. [CrossRef]

38. Galinski, M.; Lewandowski, A.; Stepniak, I. Ionic liquids as electrolytes. Electrochim. Acta 2006, 51, 5567-5580.

39. O'Mahony, A.M.; Silvester, D.S.; Aldous, L.; Hardacre, C.; Compton, R.G. Effect of water on the electrochemical window and potential limits of room-temperature ionic liquids. J. Chem. Eng. Data 2008, 53, $2884-2891$. [CrossRef] 
40. Chavan, S.N.; Tiwari, A.; Nagaiah, T.C.; Mandal, D. Ether and siloxane functionalized ionic liquids and their mixtures as electrolyte for lithium-ion batteries. Phys. Chem. Chem. Phys. 2016, 18, 16116-16126. [CrossRef]

41. Schröder, U.; Wadhawan, J.D.; Compton, R.G.; Marken, F.; Suarez, P.A.Z.; Consorti, C.S.; de Souza, R.F.; Dupont, J. Water-induced accelerated ion diffusion: Voltammetric studies in 1-methyl-3-[2,6-(S)-dimethylocten-2-yl]-imidazolium tetrafluoroborate, 1-butyl-3-methyl-imidazolium tetrafluoroborate and hexafluorophosphate ionic liquids. New J. Chem. 2000, 24, 1009-1015. [CrossRef]

42. Wang, Y.L.; Sarman, S.; Kloo, L.; Antzutkin, O.N.; Glavatskih, S.; Laaksonen, A. Solvation structures of water in trihexyltetradecylphosphonium-orthoborate ionic liquids. J. Chem. Phys. 2016, 145, 064507. [CrossRef]

43. Silvester, D.S.; Compton, R.G. Electrochemistry in room temperature ionic liquids: A review and some possible applications. Z. Phys. Chem. 2006, 220, 1247-1274. [CrossRef]

44. Mun, J.; Jung, Y.S.; Yim, T.; Lee, H.Y.; Kim, H.; Kim, Y.G.; Oh, S.M. Electrochemical stability of bis(trifluoromethanesulfonyl)imide-based ionic liquids at elevated temperature as a solvent for a titanium oxide bronze electrode. J. Power Sources 2009, 194, 1068-1074. [CrossRef]

45. Xue, Z.; Qin, L.; Jiang, J.; Mu, T.; Gao, G. Thermal, electrochemical and radiolytic stabilities of ionic liquids. Phys. Chem. Chem. Phys. 2018, 20, 8382-8402. [CrossRef]

Sample Availability: Samples of the ionic liquids are available from the authors. 